\title{
RESUME PEMBUATAN PROGRAM APLIKASI BORLAND DELPHI7.0 BERBASIS PAPERLAIN
}

\section{Gillan Fatahillah}

175100008

Universitas Mitra Indonesia, Sistem informasi

Gillanfatahillah.student@umitra.ac.id

\begin{abstract}
Abstrak
Penggunaan teknologi oleh manusia di awali dengan pengubahan sumber daya alam menjadi alat-alat sederhana penemuan prasejarah tentang kemampuan mengendalikan api telah menaikan ketersedian sumber-sumber pangan, sedangkan penciptaan roda telah membantu manusia dalam memperjalan dan mengendalikan lingkungan sebaliknya dengan perkembangan teknologi yang sangat pesat dan baik yang mempunyai berbagai macam program dan aplikasi

Pengujian adalah suatu proses pelaksanaan suatu program dengan tujuan menemukan suatu kesalahan. Suatu kasus test yang baik adalah apabila test tersebut mempunyai kemungkinan menemukan sebuah kesalahan yang tidak terungkap.
\end{abstract}

\section{CAPTURE PEMROGRAMAN :}

1. Fortal

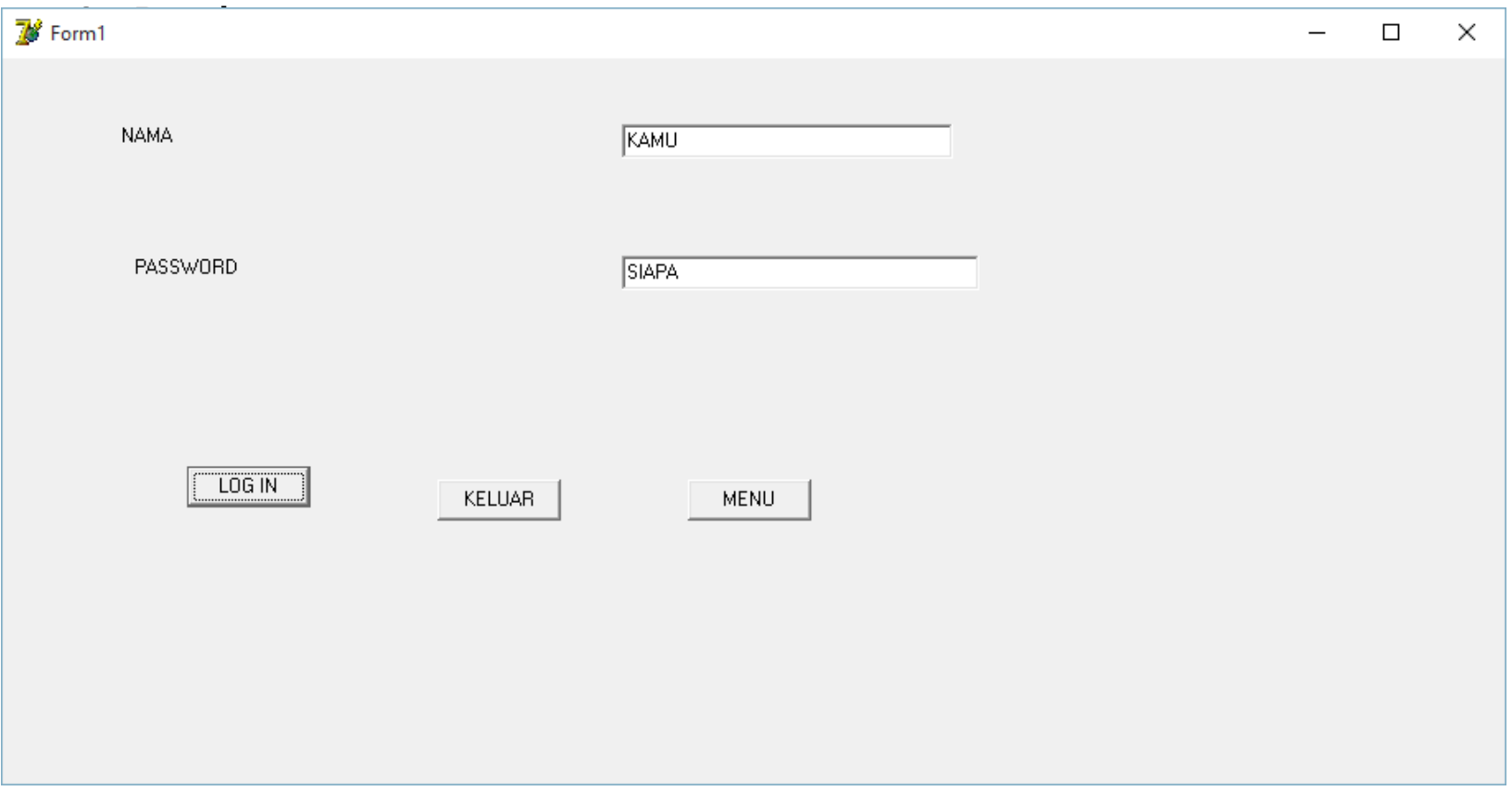


2. Menu

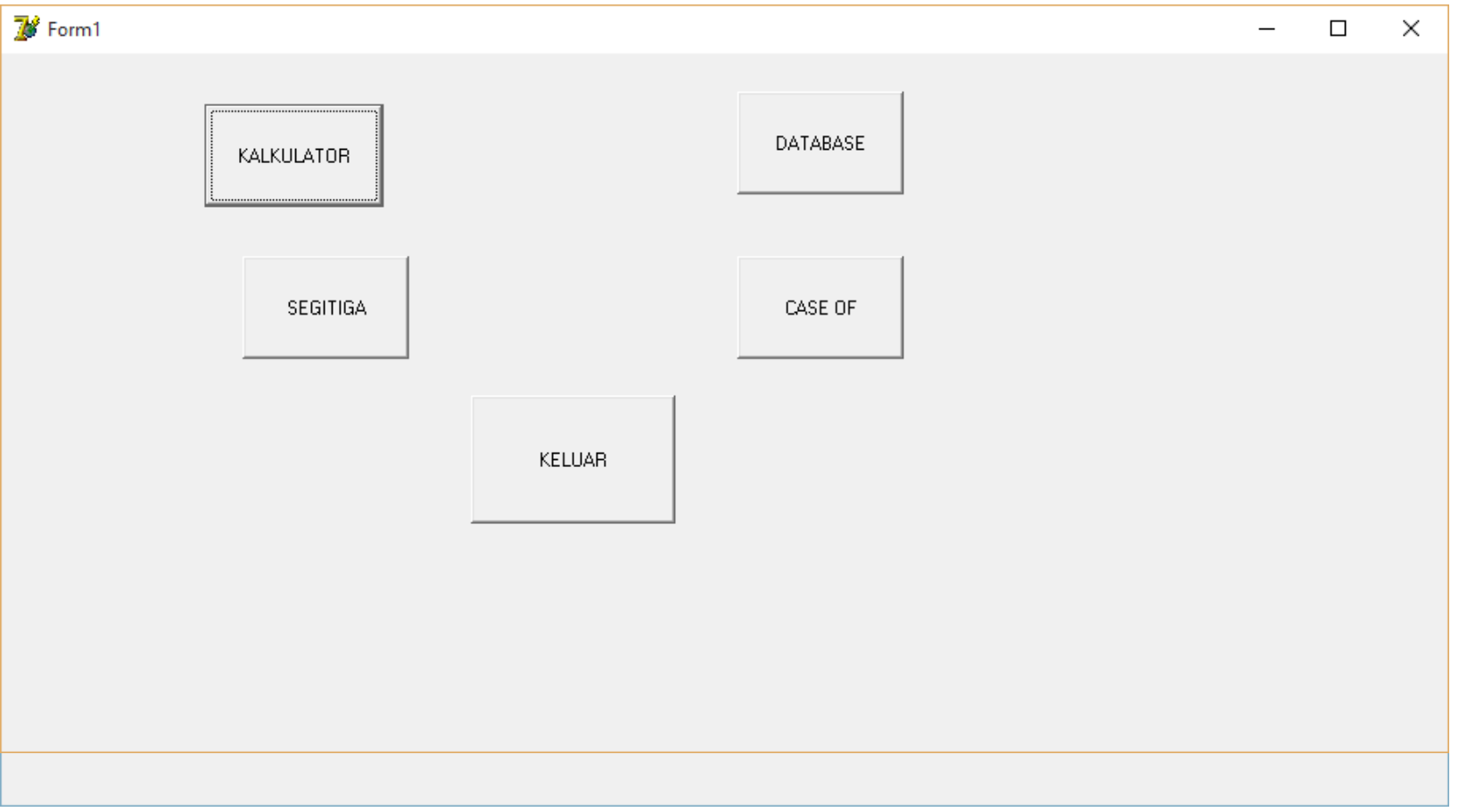

3. Kalkulator

BILANGAN

BILANGAN2

HASII

$$
9
$$

9

81
MENU

ULANG

KELUAR
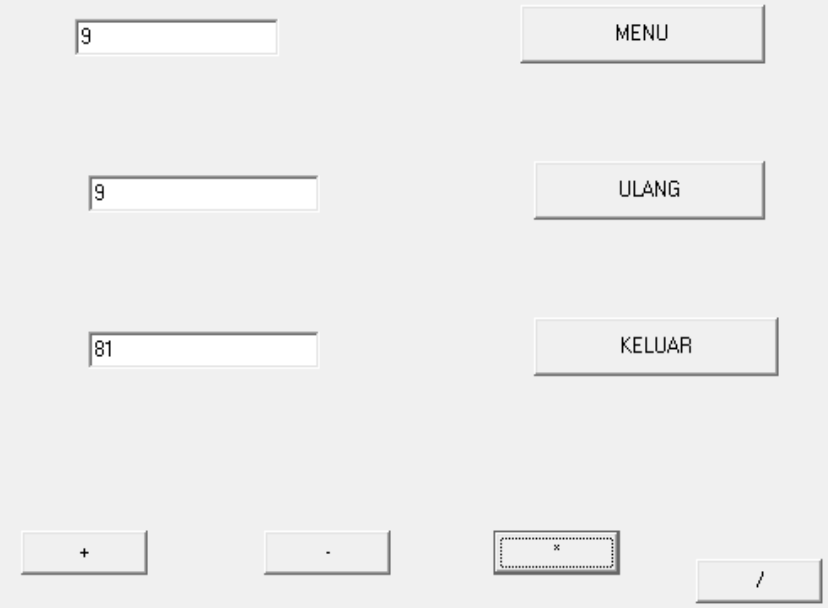


\section{Segitiga}

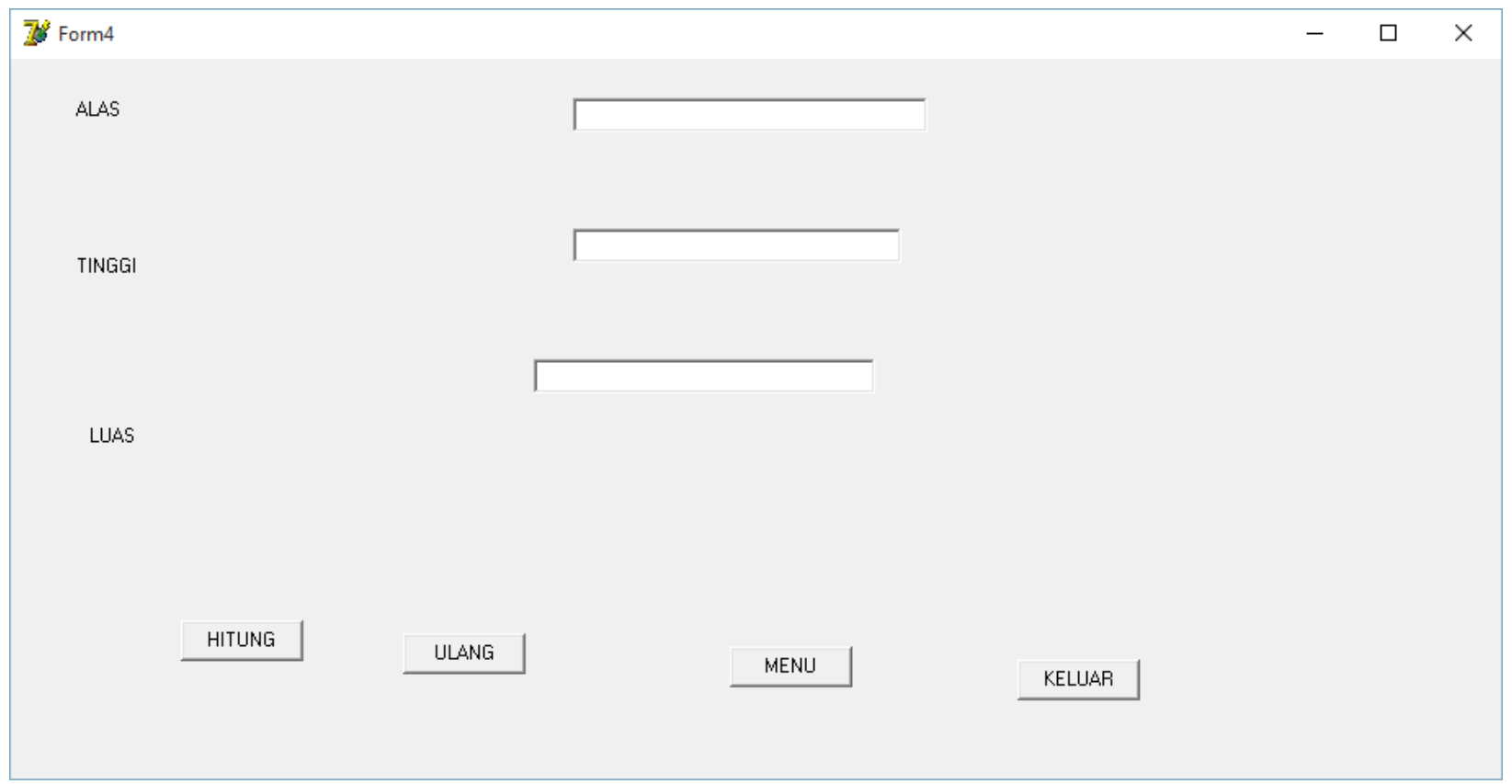

5. Case of 


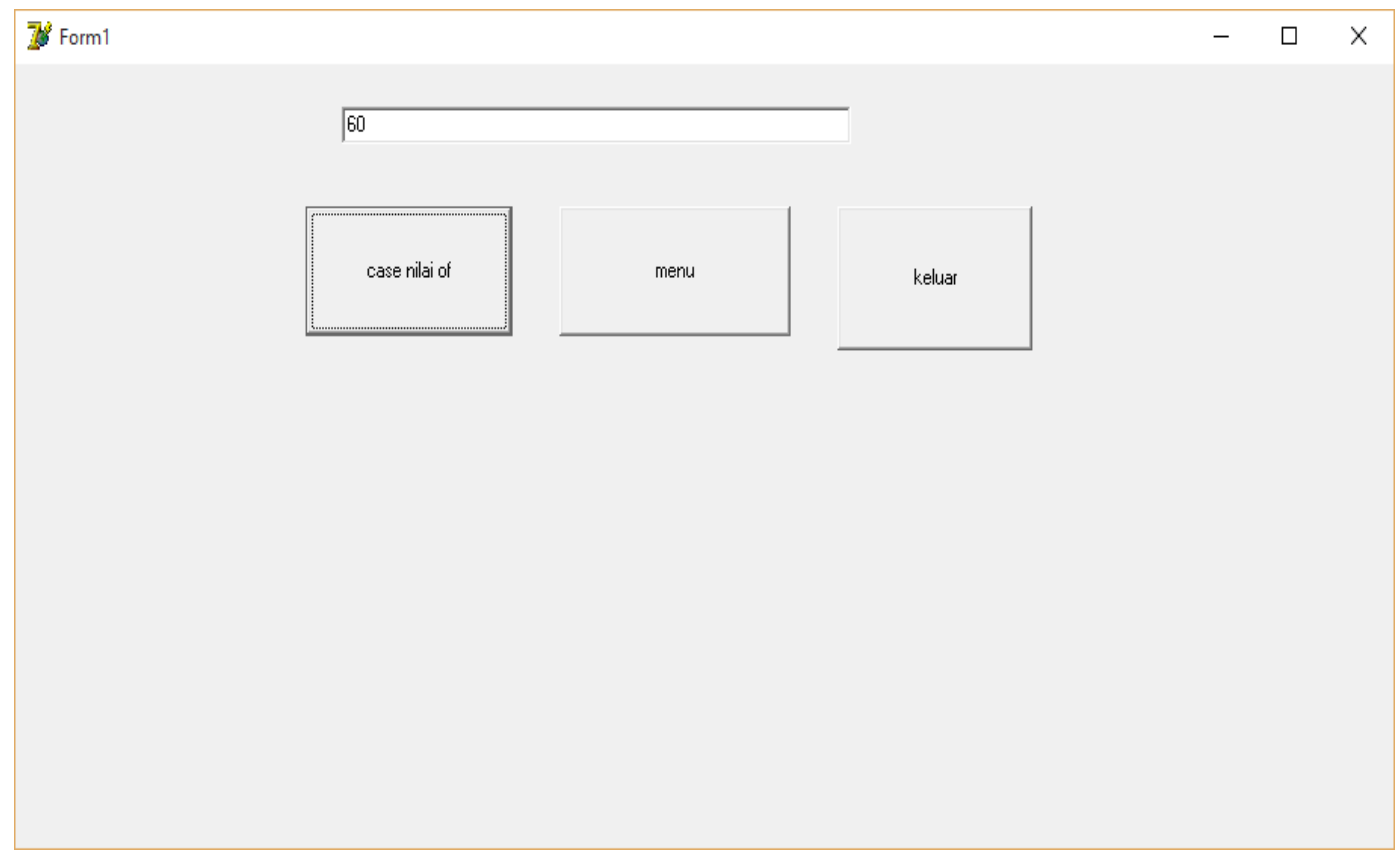

6. Database

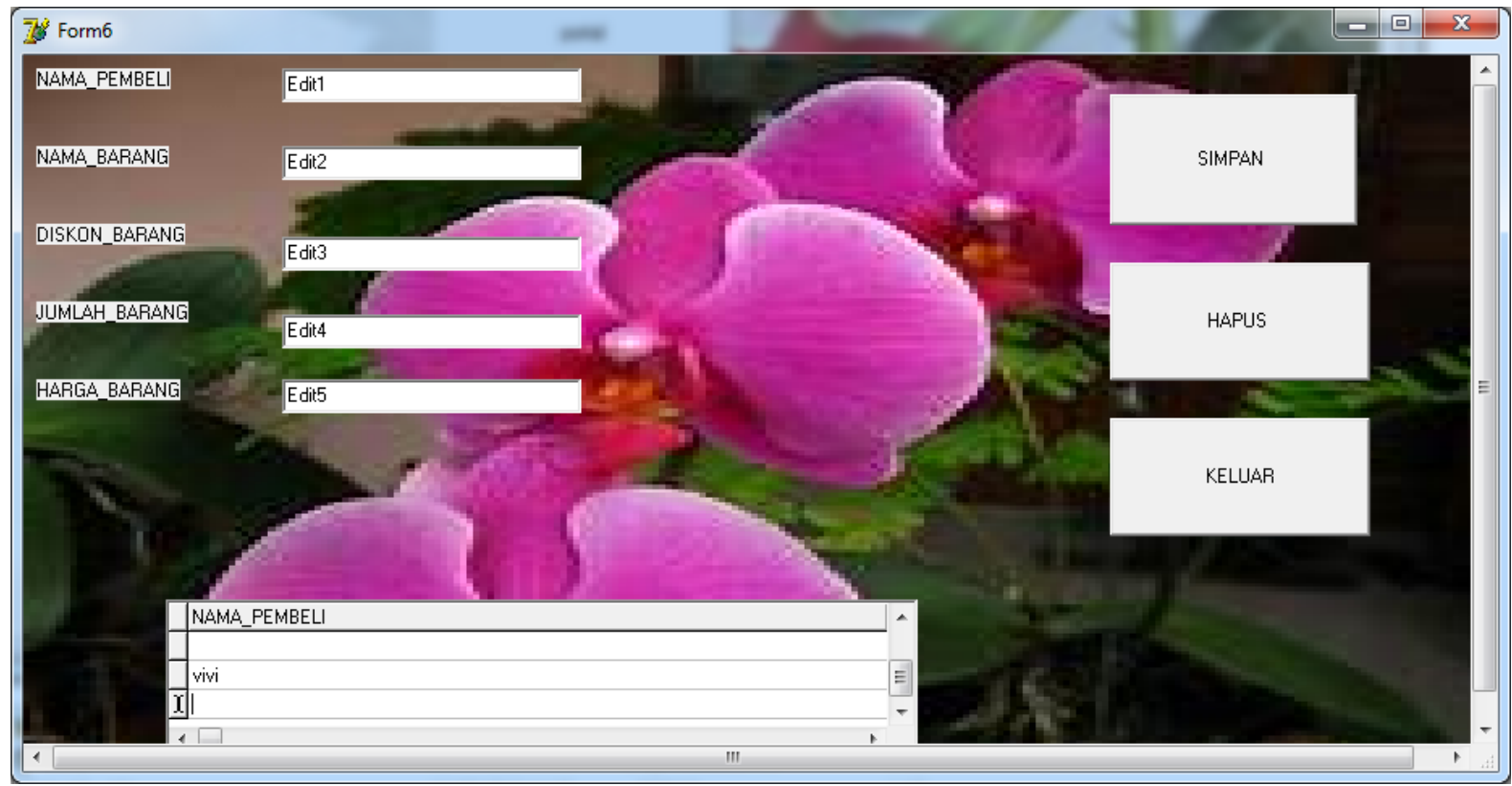

PENJELASAN : 


\section{MENU}

Menu adalah

Merupakan kumpulan perintah yang sudah dikelompokkan menjadi satu, berdasarkan fungsinya masing masing,

\section{Portal}

Adalah penyedian kandungan informasi yang dapat diakses menggunakan beragam perangkat, misalnya computer pibadi, computer jinjing, (notebook) PDA (personal digital assistant) atau bahkan telepon genggam.

\section{3. kalkulator}

Adalah alat untuk menghitung dari perhitungan sederhana seperti penjumlahan, pengurangan, perkalian, dan pembagian, sampai kepada kalkulator, sains yang dapat menghitung rumus matematika tertentu.

\section{Segitiga}

Adalah bangun datar yang dibentuk oleh 3 garis lurus yang saling berpotongan. Segitiga dibentuk oleh 3 titik sudut yang letak nya tidak segaris dihubungkan.

\section{Case Of}

Case of pada pascal, case of adalah bahasa pemrograman agar output pada pemrograman pascal mengikuti sesuai dengan input.

\section{Database}

Kumpulan data yang disimpan secara sistematis didalam computer yang dapat diolah atau dimanupulasi menggunakan perangkat lunak (program aplikasi ) untuk mengasil kan informasi.

A. DISKUSI

Dalam pembuatan sebuah program sangat membutuh ketelitian, seorang programer harus sangat teliti dalam penulisan coding jika ada sedikit pun coding yang salah makan program yang kita buat tidak runing / jalan. 
B. REFERENSI

1. A. S. Putra And O. M. Febriani, "Knowledge Management Online Application In Pdam Lampung Province," In Prosiding International Conference On Information Technology And Business (Icitb), 2018, Pp. 181-187.

2. A. S. Putra, O. M. Febriani, And B. Bachry, "Implementasi Genetic Fuzzy System Untuk Mengidentifikasi Hasil Curian Kendaraan Bermotor Di Polda Lampung," J. Sist. Inf. Dan Manaj. Basis Data, Vol. 1, No. 1, Pp. 21-30, 2018.

3. O. M. Febriani And A. S. Putra, "Sistem Informasi Monitoring Inventori Barang Pada Balai Riset Standardisasi Industri Bandar Lampung," J. Inform., Vol. 13, No. 1, Pp. 90-98, 2014.

4. Putra, Arie Setya. "2018 Artikel Struktur Data, Audit Dan Jaringan Komputer." (2018).

5. Putra, A. S. (2018, July 17). Paperplain Fundamental Create Application With Borland Delphi 7.0 University Of Mitra Indonesia. Retrieved From Osf.Io/Pbrn9. 